\title{
Medical Journal of Clinical Trials \& Case Studies
}

ISSN: 2578-4838

\section{Eagles Syndrome}

\section{Vijayendranath $\mathrm{N}^{1}$, Raghavendra $\mathrm{K}^{2}$, Prasanna $\mathrm{KR}^{3}$, Gowri $\mathrm{B}^{4}$, Roopashri Rajesh $\mathrm{K}^{4}$, Devika $\mathrm{S}^{4}$ and Devishree VR5}

1Postgraduate, Department of Oral Medicine and Radiology, A.J Institute of Dental Sciences, India

${ }^{2}$ Professor and Head, Department of Oral Medicine and Radiology, A.J Institute of Dental Sciences, India

${ }^{3}$ Professor, Department of Oral Medicine and Radiology, A.J Institute of Dental Sciences, India

${ }^{4}$ Reader, Department of Oral Medicine and Radiology, A.J Institute of Dental Sciences, India

${ }^{5}$ Assistant Professor, Department of Oral Medicine and Radiology, A.J Institute of Dental Sciences, India

*Corresponding author: Vijayendranath Nayak S, Postgraduate, Department of Oral Medicine and Radiology, A.J Institute of Dental Sciences, Kuntikana, Mangaluru, Karnataka, India, Tel: +918197588777; E-mail: drnayakomr@gmail.com

\section{Abstract}

Eagles syndrome is the term given to the symptomatic elongation of the styloid process, mineralization of the stylohyoid or stylomandibular ligament or posterior belly of the digastric muscle causing recurrent throat pain, foreign body sensation, dysphagia or facial pain. This clinical report describes the diagnosis of a rare case using Orthopantomograph which is widely used for diagnosis.

Keywords: Eagles Syndrome; Elongated Styloid Process; Orthopantomograph; Pathophysiology; Genetical

\section{Introduction}

Pietro Marchetti observed an elongation of the styloid process in the 17 th century but in 1937 it was Watt W. Eagle who first described stylalgia, later called the Eagle syndrome. Eagle syndrome is characterized by facial and neck pain but may also manifest itself in a variety of symptoms such as dysphagia, tinnitus, otalgia, syncope and focal cerebral symptoms [1,2]. The etiology and the pathophysiology of the syndrome are poorly understood. The clinical diagnosis is difficult and radiologic confirmation is required. The surgical treatment is highly effective. Herin we report a case with unilateral elongation of styloid process [2-6].

\section{Case Report}

A 32year old female patient reported to the department of oral medicine and radiology with a chief complaint of throat pain and pain on moving her head towards right side. Patient also gave history of intermittent type of shoulder pain. She also had a sense of fullness in her neck. Past medical and dental history was not significant. Extra oral examination revealed tenderness on palpating the right auricular region. Introral examination revealed tenderness on palpating the right tonsillar fossa. A provisional diagnosis of eagles syndrome was given. Orthopantomogram was advised which revealed elongated right styloid process measuring 


\section{Medical Journal of Clinical Trials \& Case Studies}

$38.2 \mathrm{~mm}$ (Figure 1A \& 1B). Hence a final diagnosis of eagle's syndrome was given. Patient was referred to the department of ENT for further evaluation.

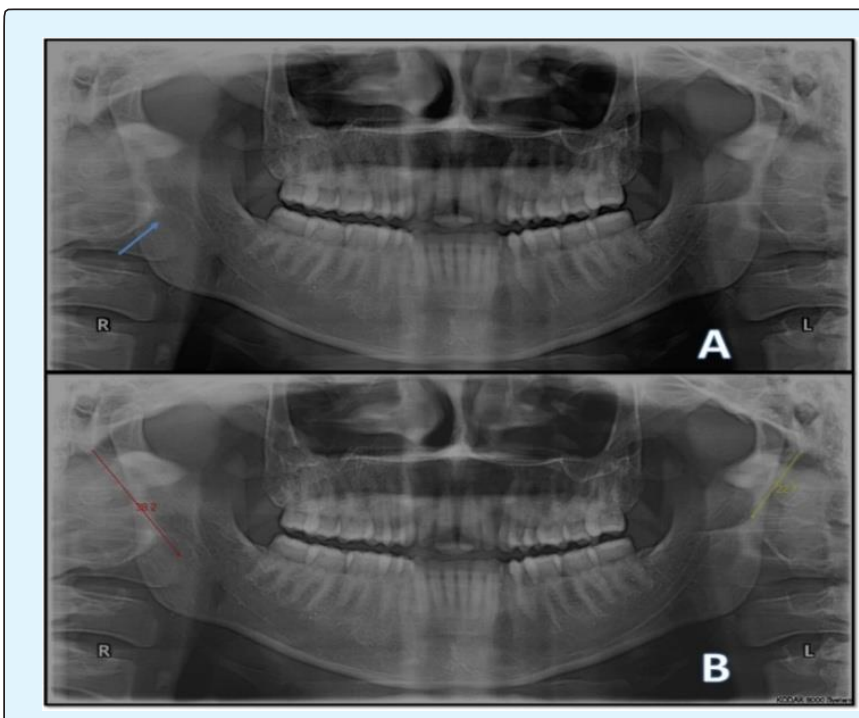

Figure 1A: OPG revealing elongated right styloid process.

Figure 1B: OPG revealing measurements of right and left styloid process.

\section{Discussion}

The styloid process and the stylohyoid ligament are derived from Reichert's cartilage, which arises from the second pharyngeal arch. Reichert's cartilage is divided into tympano-hyal, stylo-hyal, cerato-hyal and hypo-hyal parts. The ossification of the stylo-hyal part and its fusion with the tympano-hyal part causes a long styloid process. Different theories such as post-traumatic reactive hyperplasia and metaplasia, anatomical variations, postmenopausal endocrine dysfunction and genetical transmission are proposed to explain this abnormal ossification but the exact cause of the Eagle syndrome is still not clear. Murtagh, et al. presented three etiologic theories to explain the development of Eagles syndrome $[7,8]$. The first theory is congenital elongation of the styloid process due to the persistence of the cartilaginous precursor, the second is the calcification of the stylohyoid ligament by a mysterious process, and the third is the growth of osseous tissue at the insertion of the stylohyoid ligament.

Steinmann proposed three mechanisms that might case ossification:

1) Reactive hyperplasia, when trauma activates the remnants of the original connective and fibrocartilaginous cells.
2) Reactive metaplasia, or an abnormal healing following a trauma that initiates ossification of the stylohyoid ligament.

3) Anatomic variance, which occurs without any distinctive trauma [9].

Camarda, et al. proposed a fourth mechanism of aging developmental anomaly in the absence of apparent radiographic ossification [10].

The diagnosis is based on the clinical signs, digital palpation of the styloid process in the tonsillar fossa, radiological findings and lidocaine infiltration test [11].

The differential diagnosis includes migraine and other headaches, trigeminal neuralgia, glossopharyngeal neuralgia of sphenopalatine ganglia, tonsillitis and otitis, degenerative diseases causing neck pain, psychosomatic diseases, inflammatory and neoplastic processes in the oropharyngeal area, laryngopharyngeal dysesthesia, temporomandibular arthritis, chronic tonsillopharyngitis, hyoid bursitis, Sluder's syndrome, histamine cephalgia, cluster type headache, esophageal diverticula, temporal arteritis, cervical vertebral arthritis, benign or malign neoplasms, and migraine type headache [12].

The normal length of the styloid process is estimated to be $25 \mathrm{~mm}$ by Eagle $[12,13]$. In further research; the average sizes varying from $26 \mathrm{~mm}$ to $30 \mathrm{~mm}$ are reported [2]. Generally, if the length of the styloid process is more than $30 \mathrm{~mm}$, it is considered to be elongated. In our reported case right styloid process was elongated, measuring about $38.2 \mathrm{~mm}[14,15]$.

Eagle's syndrome is characterized by the following symptoms: pharyngeal pain localized in the tonsillar fossa, radiating to the esophagus, to the hyoid bone, painful head rotation and lingual movements. The pain is exacerbated by swallowing and chewing and foreign body sensation (Globus hystericus). Elongation of styloid process can be unilateral or bilateral. In the above reported case all the above mentioned classical symptoms were present except globus hystericus and pain on lingual movements. Enlargement of styloid process was seen unilaterally [16].

Eagles syndrome can be treated non-surgically and surgically. A pharmacological approach includes transpharyngeal infiltration of steroids or anesthetics into the tonsillar fossa. In addition, there are two surgical approaches, intraoral and extraoral. In the intraoral approach, the styloid process in tonsillar fossa is palpated, the overlying mucosa and superior constrictor muscle are incised vertically, and the styloid processes are dissected 


\section{Medical Journal of Clinical Trials \& Case Studies}

out, resected using a rongeur forceps. If necessary for exposure, a standard tonsillectomy should be performed first. The intraoral approach is good for aesthetic consideration as external scarring is avoided and for shorter operative times. Nevertheless, exposure of the retropharyngeal spaces to intraoral contents increases the infection risk. The intraoral approach also has the disadvantages of poor access, as in cases of trismus, and risk of intraoperative injury. An extraoral approach involves making a cervical incision from the proximal portion of the sternocleidomastoid muscle to the hyoid bone, and then dissecting and removing the styloid process. The external approach has the advantage of good anatomic exposure of the styloid process. However, it requires more intervention and results in a visible scar $[16,17]$.

\section{Conclusion}

Diagnosis has always been a challenging task for any medical professional, same holds good in diagnosis of eagles syndrome. Pain being the main concern of the patient, making them free from the same has always been a challenging task. Radiographic investigations have proved to be beneficial in diagnosis of this atypical type of enlargement of styloid, so effective treatment planning can be done for achieving best results.

\section{References}

1. Fini G, Gasparini G, Filippini F, Becelli R, Marcotullio $M$ (2000) The long styloid process syndrome or Eagle's syndrome. Journal of Cranio-Maxillofacial Surgery 28(2): 123-127.

2. Eagle WW (1937) Elongated sytoid process: Report of two cases. Archives of Otolaryngology 25: 584-587.

3. Bafaqeeh SA (2000) Eagle syndrome: classic and carotid artery types. J Otolaryngol 29(2): 88-94.

4. Zuber M, Meder JF, Mas JL (1999) Carotid artery dissection due to elongated styloid process. Neurology 53(8): 1886-1887.

5. Chuang WC, Short JH, McKinney AM, Anker L, Knoll B, et al. (2007) Reversible left hemispheric ischemia secondary to carotid compression in Eagle syndrome: surgical and CT angiographic correlation. AJNR Am J Neuroradiol 28(1): 143-145.
6. Dao A, Karnezis S, Lane JS 3rd, Fujitani RM, Saremi F (2011) Eagle syndrome presenting with external carotid artery pseudoaneurysm. Emerg Radiol 18(3): 263-265.

7. Steinmann EP (1970) A new light on the pathogenesis of the styloid syndrome. Arch Otolaryngol 91(2): 171174.

8. Lorman JG, Biggs JR (1983) The Eagle syndrome. AJR Am J Roentgenol 140(5): 881-882.

9. Murtagh RD, Caracciolo JT, Fernandez G (2001) CT findings associated with Eagle syndrome. AJNR Am J Neuroradiol 22(7): 1401-1402.

10. Steinmann EP (1968) Styloid syndrome in absence of an elongated process. Acta Otolaryngol 66(4): 347356.

11. Camarda AJ, Deschamps C, Forest D (1989) I. Stylohyoid chain ossification: a discussion of etiology. Oral Surg Oral Med Oral Pathol 67(5): 508-514.

12. Piagkou M, Anagnostopoulou S, Kouladouros $\mathrm{K}$, Piagkos G (2009) Eagle's syndrome: a review of the literature. Clin Anat 22(5): 545-558.

13. Harma R (1966) Stylalgia: clinical experiences of 52 cases. Acta Otolaryngol 224: 149.

14. Gözil R, Yener N, Calgüner E, Araç M, Tunç E, et al. (2001) Morphological characteristics of styloid process evaluated by computerized axial tomography. Ann Anat 183(6): 527-535.

15. Yavuz H, Caylakli F, Yildirim T, Ozluoglu LN (2008) Angulation of the styloid process in Eagle's syndrome. Eur Arch Otorhinolaryngol 265(11): 1393-1396.

16. Leclerc JE (2008) Eagle syndrome: teaching the intraoral surgical approach with a 30 degrees endoscope. J Otolaryngol Head Neck Surg 37: 727729.

17. Yavuz H, Caylakli F, Erkan AN, Ozluoglu LN (2011) Modified intraoral approach for removal of an elongated styloid process. J Otolaryngol Head Neck Surg 40(1): 86-90. 